\title{
Odontogenic Keratocyst, Orthokeratinized Odontogenic Cyst and Epidermal Cyst: An Immunohistochemical Study Including Markers of Proliferation, Cytokeratin and Apoptosis Related Factors
}

\author{
Yasuyuki Koizumi \\ Department of Pathology, Nihon University School of Dentistry at Matsudo, Chiba 271-8587, Japan
}

Correspondence to: Yasuyuki Koizumi

E-mail: koizumi@mascat.nihon-u.ac.jp

Key words:

odontogenic keratocyst, orthokeratinized odontogenic keratocyst, epidermal cyst, Ki-67, cytokeratin, bcl-2, Bax

\begin{abstract}
Objective: There are microscopic similarities among odontogenic keratocyst (OKC), orthokeratinized odontogenic keratocyst (OOC) and epidermal cyst (EDC). This study was to compare with cell proliferation, cell differentiation and apoptosis related factors in OKC, OOC and EDC in order to clarify the characters and category of three hitstopathologically similar cysts.

Material and Methods: Fourteen cases of OKC, nine cases of OOC and eighteen cases of EDC were examined immunohistochemically using antibodies against Ki-67, cytokeratins (CK7, 10, 10/13, 17, 18, 19, 20) and apoptosis related factors (bcl-2 and Bax).

Results: Ki-67 labeling index in OKC was statistically higher than that in $\mathrm{OOC}$ and EDC $(p<0.05)$. And that in OOC was higher in EDC $(p<0.05)$. In OKC, CKs and bcl-2 expression patterns were different from OOC and EDC, while both OOC and EDC showed similar reactivity with CKs and bcl-2.

Conclusions: The present results suggested that OKC had high cellular proliferation and was relatively low differentiation as compare with OOC and EDC. In addition, there was participation of apoptosis suppressor in OKC. The character of OOC occupied an intermediate position between OKC and EDC. Therefore, it was possible to consider OOC as a distinct entity from OKC. EDC had the lowest cellular activity in the three cysts and it was comparatively maturated lesion.
\end{abstract}

\section{Introduction}

Odontogenic keratocyst $(\mathrm{OKC})$ is a histologically distinct type of developmental odonotogenic cyst that commonly occurs in the tooth-bearing area or in the retromolar region of the jaws (1-4). OKC is characterized clinically by its aggressive behavior and high tendency for local recurrence $(4,5)$. Microscopically, OKC consists of a uniform epithelial lining with a well-developed basal cell layer and a corrugated parakeratinized surface $(1,4)$. Recent studies have discussed the histologic variants (parakeratin vs. orthokeratin) of OKC (3,5-9). Microscopically, the majority of OKC are parakeratinized OKC and orthokeratinized OKCs are only $12.2 \%$ (5). In addition, some investigators described that orthokeratinized OKC had clincopathologically less recurrence rate as compare with parakeratinized OKC and therefore it should be placed into a different category $(5,6,8)$. Moreover a few researchers designated orthokeratinized OKC as orthokeratinized odontogenic cyst (OOC) $(1,8,9)$. On the other hand, epidermal cyst (EDC) is a common cyst of the skin that is lined by epidermis-like epithelium $(1,2)$. These three types of keratinized cysts show similar histopathological features $(7,10)$

Keratinocyte has a self-duplication cycle. Old cells become to keratin and they come off the epithelial surface. The cells which appear by mitosis make basal layer, spinous layer and keratinization layer. Keratinocyte continues this process repeatedly (11).

Kerr suggested the concept of apoptosis in 1972 (12). The cell's life cycle is constituted of cell growth, cell differentiation and cell apoptosis. Especially, squamous epithelium repeatedly exhibits cell proliferation, cell differentiation and apoptosis (11).

This study was to compare with cell proliferation, cell differentiation and apoptosis related factors in $\mathrm{OKC}, \mathrm{OOC}$ and EDC in order to clarify the characters and category of three hitstopathologically similar cysts. 
Table 1. Clinical characteristics of the present cases

\begin{tabular}{|c|c|c|c|c|}
\hline Classification & Case & Age & Sex & Location \\
\hline \multirow[t]{14}{*}{$\mathrm{OKC}$} & 1 & 30 & Male & Right maxilla, molar area \\
\hline & 2 & 20 & Female & Left mandible, molar area \\
\hline & 3 & 62 & Male & Right mandible, molar area \\
\hline & 4 & 57 & Male & Right/left mandible, anterior/molar area \\
\hline & 5 & 20 & Female & Left mandible, molar area \\
\hline & 6 & 32 & Female & Right mandible, molar area \\
\hline & 7 & 59 & Female & Right maxilla, premolar-molar area \\
\hline & 8 & 22 & Female & Left mandible, molar area \\
\hline & 9 & 26 & Female & Left mandible, molar area \\
\hline & 10 & 60 & Female & Left maxilla, molar area \\
\hline & 11 & 27 & Male & Right mandible, premolar-molar area \\
\hline & 12 & 26 & Female & Left mandible, molar area \\
\hline & 13 & 16 & Male & Left mandible, premolar-molar area \\
\hline & 14 & 28 & Female & Right mandible, premolar-molar area \\
\hline \multirow[t]{9}{*}{$\mathrm{OOC}$} & 1 & 25 & Male & Right mandible, molar area \\
\hline & 2 & 46 & Female & Left mandible, molar area \\
\hline & 3 & 20 & Male & Right maxilla, molar area \\
\hline & 4 & 45 & Male & Right mandible, molar area \\
\hline & 5 & 31 & Male & Left maxilla, premolar area \\
\hline & 6 & 29 & Female & Right maxilla, molar area \\
\hline & 7 & 57 & Male & Left maxilla, molar area \\
\hline & 8 & 44 & Male & Right maxilla, molar area \\
\hline & 9 & 27 & Male & Right maxilla, molar area \\
\hline \multirow[t]{18}{*}{$\mathrm{EDC}$} & 1 & 26 & Male & Left neck \\
\hline & 2 & 25 & Female & Right neck \\
\hline & 3 & 48 & Male & Right infraorbital area \\
\hline & 4 & 70 & Male & Left back \\
\hline & 5 & 52 & Female & Left infraorbital area \\
\hline & 6 & 36 & Female & Right back \\
\hline & 7 & 44 & Female & Right neck \\
\hline & 8 & 48 & Female & Right cheek \\
\hline & 9 & 65 & Female & Left back \\
\hline & 10 & 41 & Male & Right abdomen \\
\hline & 11 & 39 & Male & Right breech \\
\hline & 12 & 25 & Male & Left cheek \\
\hline & 13 & 69 & Male & Left infraorbital area \\
\hline & 14 & 29 & Female & Right back \\
\hline & 15 & 24 & Male & Right ear \\
\hline & 16 & 33 & Male & Left foot, Right planta pedis \\
\hline & 17 & 64 & Male & Left scrotum \\
\hline & 18 & 63 & Female & Left back \\
\hline
\end{tabular}

\section{Materials and Methods}

Samples of fourteen cases of OKC and nine cases of OOC were obtained from the files of the Department of Pathology, Nihon University School of Dentistry at Matsudo, Japan. Eighteen cases of EDC in the skin were also obtained from the Department of Clinical Pathology, Kashiwa Hospital, Jikei University, Japan. The clinical data of each case were summarized in Table 1.

All specimens were fixed in $10 \%$ neutral buffered formalin and embedded in paraffin. Four $\mu \mathrm{m}$ thick sections were prepared and stained with hematoxylin and eosin (H \& E) using standard technique. Immunostaining was carried out with the dextran polymer method (Envison + kit, Dako Japan) on dewaxed tissue sections. The antibodies were used against Ki-67, various cytokeratin (CK 7, 10, 13, 17, 18, 19, 20) and apoptosis related factors (bcl-2 and Bax). The used antigens of original sources, clones, molecular weights and dilutions were summarized in Table 2.

All primary antibodies were diluted with Tris- $\mathrm{HCl}$ buffer (pH7.4). Normal oral mucosa, normal skin, normal salivary 
Table 2. Primary and used antibodies

\begin{tabular}{llllc}
\hline Antibody & Source & Clone & Molecular weight (kD) & Dilution \\
\hline Ki-67 & Dako Japan & Ki-67 & 345 and 395 & $1: 25$ \\
CK 7 & Dako Japan & OV-TL12/30 & 54 & $1: 25$ \\
CK 10 & Dako Japan & DE-K10 & 56.5 & $1: 50$ \\
CK 10/13* & Dako Japan & DE-K13 & 54 & $1: 50$ \\
CK 17 & Dako Japan & E3 & 46 & $1: 20$ \\
CK 18 & Dako Japan & DC10 & 45 & $1: 50$ \\
CK 19 & Dako Japan & BA17 & 40 & $1: 50$ \\
CK 20 & Dako Japan & Ks20.8 & 46 & $1: 20$ \\
bcl-2 & Dako Japan & 124 & $22 ~ 26$ & $1: 40$ \\
Bax & Dako Japan & - & 21 & $1: 25$ \\
\hline
\end{tabular}

*: In formalin-fixed paraffin-embedded tissue sections, CK13 reacts with a 54kD protein corresponding to CK 13.

duct and squamous cell carcinoma were used as positive control. Negative controls consisted of the incubation of the sections in the Tris- $\mathrm{HCl}$ buffer ( $\mathrm{pH} 7.4)$ instead of the primary antibody in the procedure.

\section{Evaluation of immunohistochemical staining}

Assessment of Ki-67 immunohistochemical staining was done using the Win roof image analysis software version 3.4 (Mitani Co. Ltd., Japan). Ki-67 immunoreactivity was assessed in areas of highest staining intensity. At least 1,000 nuclei were counted in 5 high-power fields $(\times 400)$. The $\mathrm{Ki}-67$ labeling index (number of positive cells/total cells $\times 100$ ) was calculated for the three types of cysts. Cytokeratin, bcl-2 and Bax protein immunoreactivity was divided into three categories, according to the classification of Krajewska et al. which were negative staining (-), slightly to moderately positive staining $(+)$ and strongly or intensely positive staining $(++)(13)$.

\section{Statistical analysis}

The means of Ki-67 labeling index were submitted to statistical analysis using the Kruskal-Wallis $H$-test. A $P$ value of less than 0.05 was considered statistically significant.

\section{Results}

Histopathologically, OKC showed a hyperchromatic palisaded basal cell layer and a wavy- corrugated parakeratinized layer. The epithelium and connective tissue interface were usually flat, but budding and daughter cyst were found in some cases (Fig.1a,b). Chronic inflammatory cells were partly observed in the underlying connective tissue. OOC epithelium was a stratified squamous epithelium that resembled to epidermis. Hyperkeratosis with prominent granular cell layer was indicated in the cyst-lining epithelium. The basal layer was composed of cuboidal or flattened cells, and there was no evidence of palisading or polarization of the nuclei of the basal cells that were similar to that of OKC. The epithelium consisted of a thin, uniform lining that was devoid of rete ridge formation. The surface was mostly flat. Many cases of OOC showed a connective tissue wall similar to OKC (Fig.2). EDC was lined by epidermis-like stratified squamous epithelium with welldeveloped granular cell layer, without rete ridge formation. The lumen was filled with degenerating orthokeratin substances. In some cases, a granulomatous inflammatory reaction could be seen in the cyst wall (Fig.3).

\section{Immunohistochemical findings}

The classification of epithelial cells followed Li et al (9). The results of the $\mathrm{Ki}-67$ labeling index in $\mathrm{OKC}$, OOC and EDC showed in Fig.4, and the expressions of $\mathrm{Ki}-67$ in those were summarized in Table 3 . Ki-67 positive cells in OKC were observed in the basal and predominantly suprabasal cells. The number of positive Ki-67 nuclei in OKC $(n=14)$ was $10.7 \pm 3.3 \%$ (mean \pm SD) with the ranged from 6.0 to $17.3 \%$ (Fig.5). In OOC, Ki-67-positive cells were present in both of the basal cells and the spinous cells. The number of positive Ki-67 nuclei in OOC $(n=9)$ was $8.6 \pm 2.1 \%$ (mean $\pm \mathrm{SD}$ ) with the ranged from 5.4 to $12.0 \%$ 


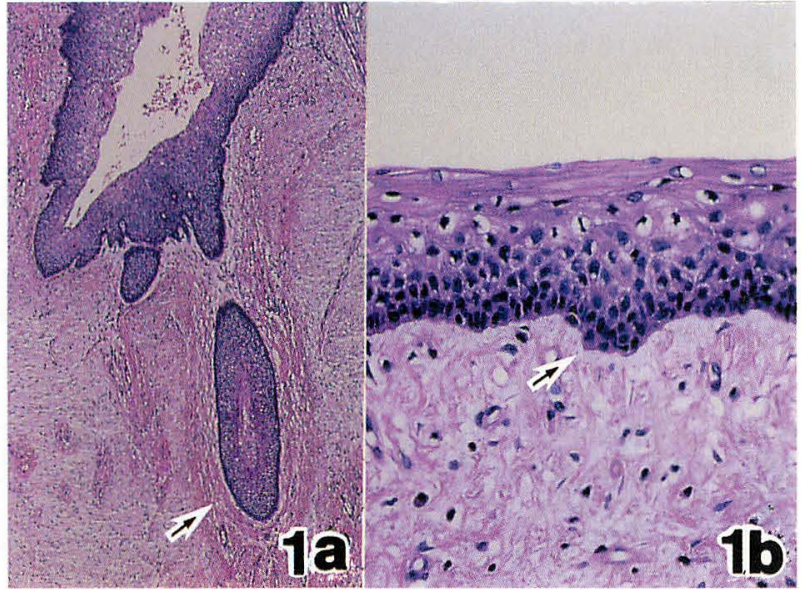

Fig. 1a. OKC case. The daughter cyst was present beneath the parakeratinized lining epithelium. H\&E original magnification $\times 100$. Fig. 1b. OKC showing parakeratinized lining with basal palisading. The budding formation was seen in the basal cells. H\&E original magnification $\times 200$.

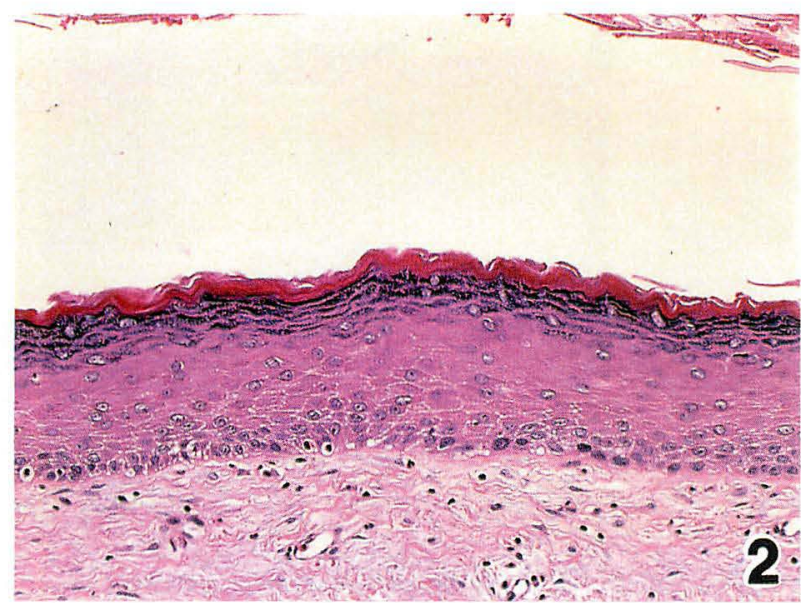

Fig. 2. OOC case. The granular cells are present. The orthokeratinized epithelium is similar to EDC. H\&E original magnification $\times 200$.

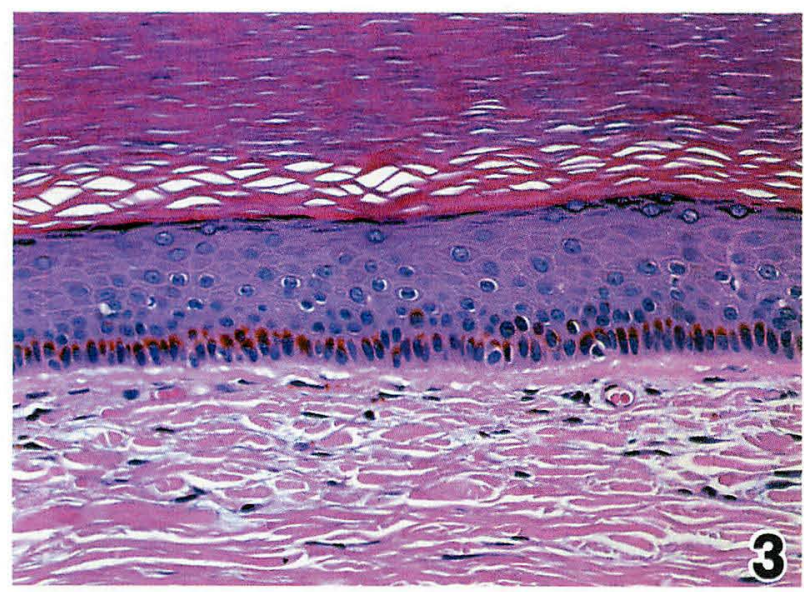

Fig. 3. EDC showing stratified squamous epithelial lining with orthokeratinization. H\&E original magnification $\times 200$.

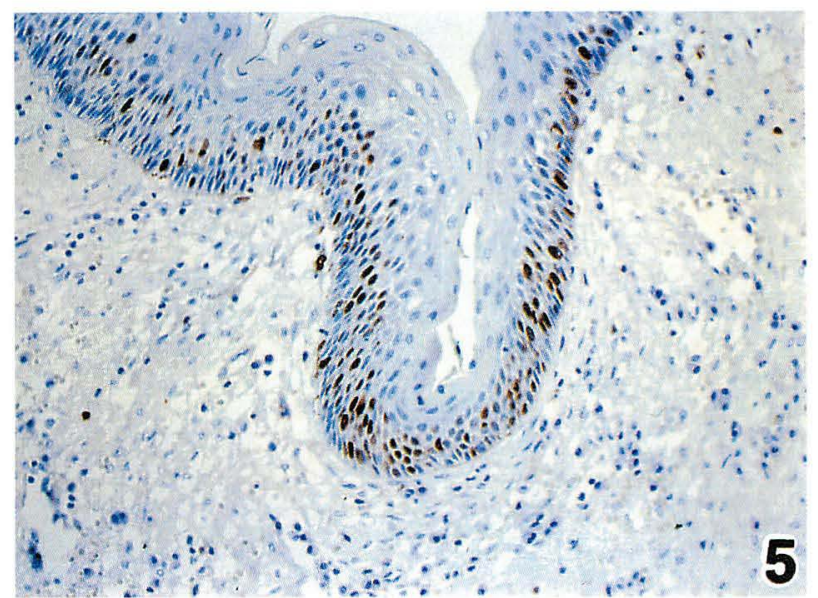

Fig. 5. Ki-67 staining of OKC. Numerous positive cells exist from nuclei of basal cells to nuclei of parabasal cells with predominance. original magnification $\times 400$.

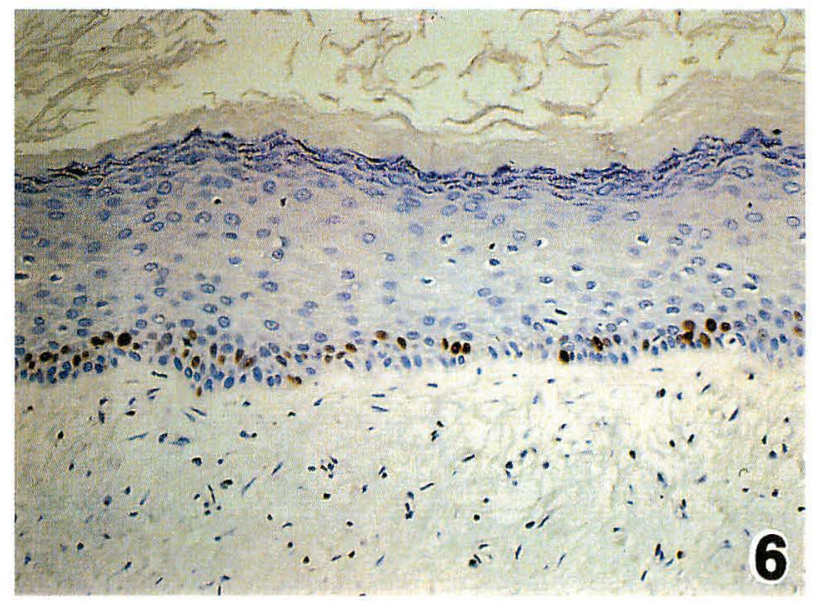

Fig. 6. Ki-67 staining of OOC. A few positive cells are observed in both nuclei of basal cells and spinous cells. original magnification $\times 400$.

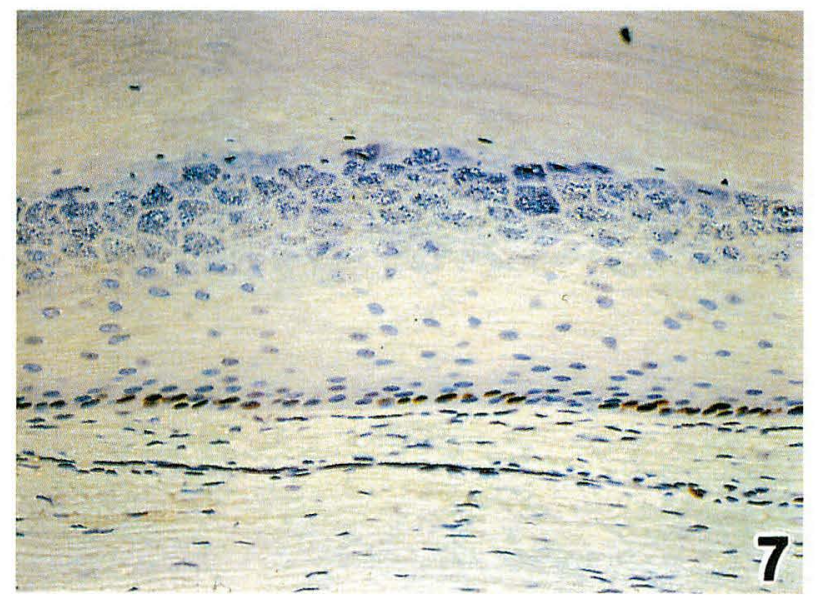

Fig.7. Ki-67 staining of EDC. Few positive cells are found in nuclei basal cells. original magnification $\times 400$. 


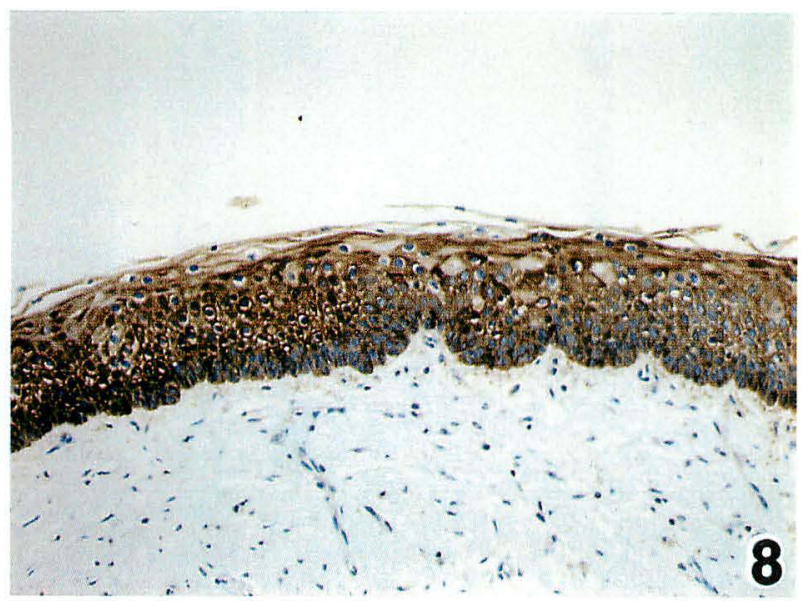

Fig. 8. Staining pattern with CK17. Strong positive reaction is observed in all epithelial cells. original magnification $\times 200$.

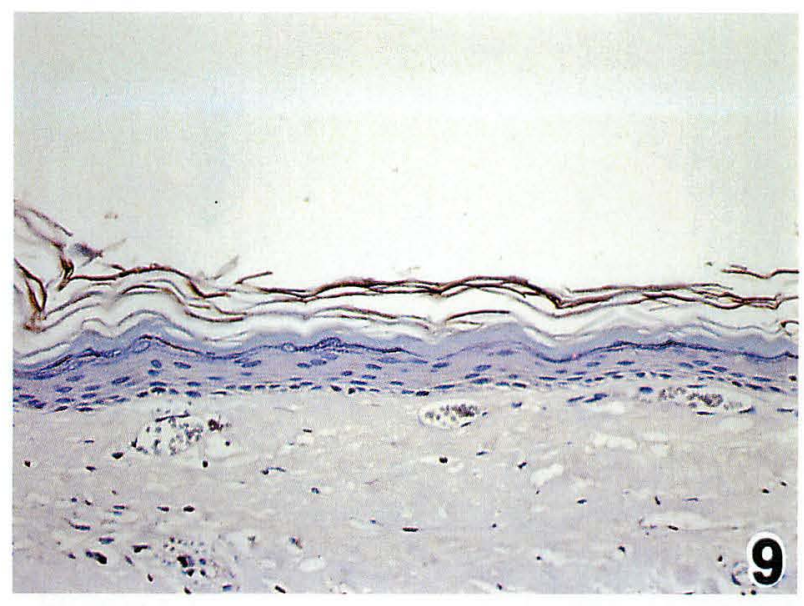

Fig. 9. Staining pattern with CK17. The positive is pronounced in the surface keratinized cells. original magnification $\times 200$.

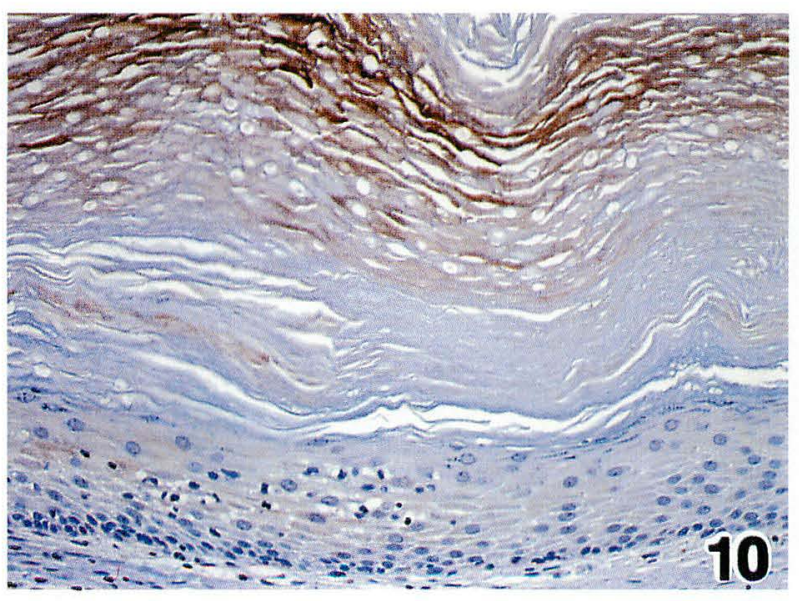

Fig. 10. Staining pattern with CK17. The reaction is limited to the surface keratinized cells. original magnification $\times 200$.

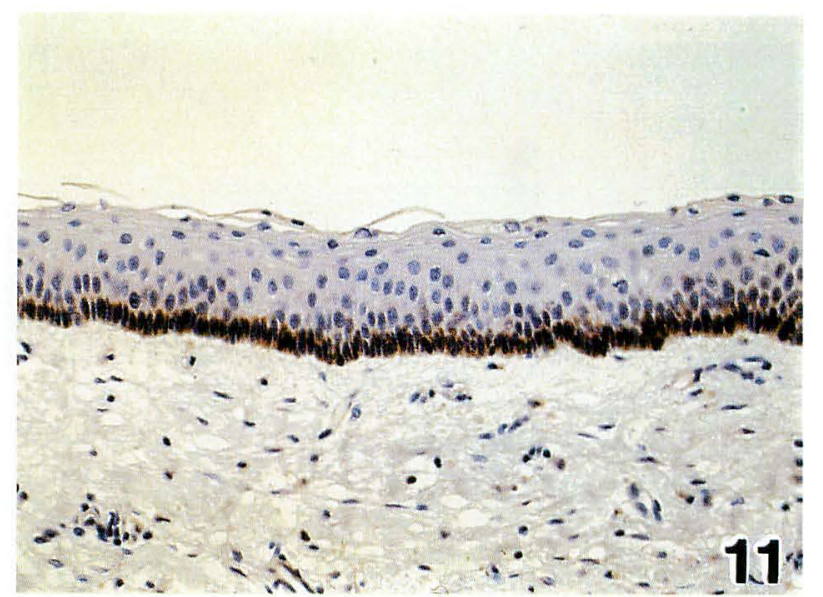

Fig. 11. The bcl-2 is evident in the cytoplasm of basal cells in OKC. original magnification $\times 200$.

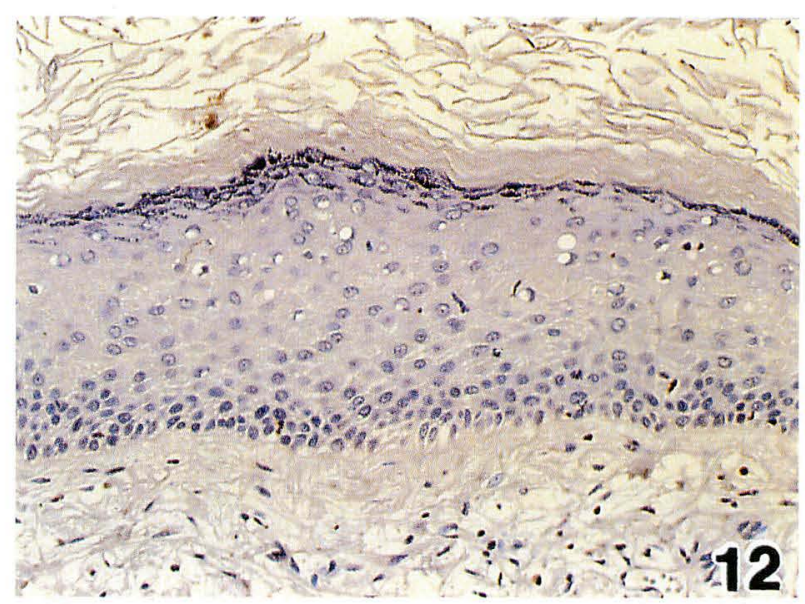

Fig. 12. The bcl-2 is absent in the OOC. original magnification $\times 200$.

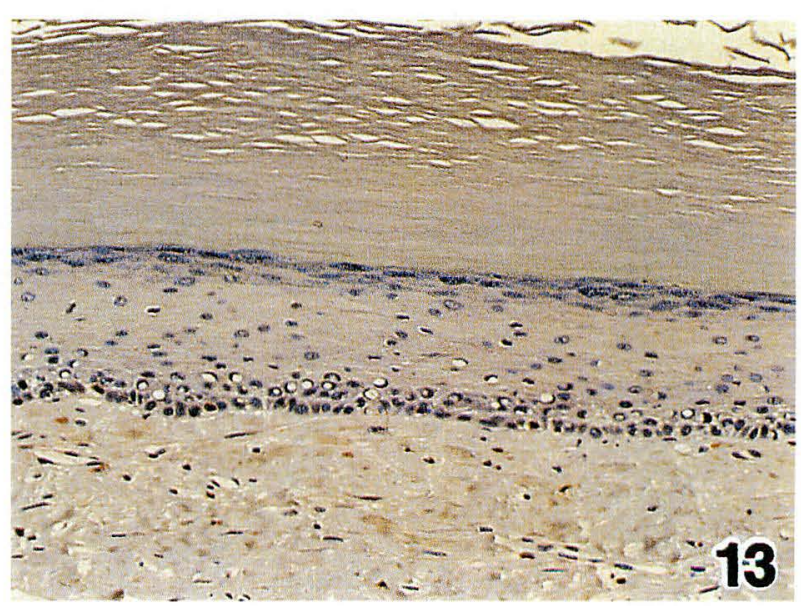

Fig. 13. The bcl-2 staining reactivity is no reaction in all epithelia of the EDC. original magnification $\times 200$. 
(Fig.6). In EDC, Ki-67 immunoreactivity was locally present in the basal layer of the lining epithelium. The number of positive Ki-67 nuclei in OOC $(n=18)$ was $5.7 \pm 2.6 \%$ (mean $+\mathrm{SD}$ ) with the ranged from 2.6 to $11.0 \%$ (Fig.7). The labelingindex in $\mathrm{OKC}$ was significantly higher than that in OOC and EDC $(p<0.05)$. And that of OOC showed a significant by higher in EDC $(p<0.05)$.

The various expression patterns of cytokeratins in $\mathrm{OKC}$, OOC and EDC were also summarized in Table 3. Although CK10 was negative reaction in OKC, both OOC and EDC were strongly positive staining in the all epitherial cells except for the basal cells. CK13 positive cells were seen in the epithelial lining of cyst. However, staining intensities were different. OKC showed intense positive staining in the upper suprabasal cells and parakeratinized cells in CK13, while in OOC staining was patchy and limited to the surface keratinized cells and the granular cells. In EDC, CK13 staining was focally present in the surface keratinized cells. CK17 staining in OKC showed a strong reaction in whole epithelium. The reaction of CK17 was prominently strong in the budding and the daughter cyst (Fig.8). Whereas in OOC and EDC, the CK17 staining patterns were almost focal reaction in the surface keratinized cells (Figs.9 and 10). Although CK 19 staining was slightly or moderately positive for the parakeratinized cells and the upper suprabasal cells in OKC, CK19 staining was negative in OOC and EDC. CK7, 18 and 20 were negative for in the lining epithelium of all cysts.

Apoptosis related factors (bcl-2 and Bax) were also designated in Table 3. The immunoexpression of bcl-2 apoptotic inhibitor was only observed in the basal cells in OKC. In addition, 13 out of the $14 \mathrm{OKC}$ were bcl-2 positive (Fig.11). However, all OOC and EDC cases were negative staining (Figs.12 and 13). Immunoreactivity for Bax proapoptotic factor tended to be similar in the three types of cysts. The expression was present in all epithelium of $\mathrm{OKC}$, however, Bax was negative for the surface keratinized cells in OOC and EDC.

\section{Discussion}

$\mathrm{OKC}$ is distinctiveness from developmental odontogenic cyst, because of its relatively aggressive behavior and high recurrence rate (1-4). The budding formation and daughter cyst were seen only in OKC which supported higher recurrence rate in $\mathrm{OKC}$. This $\mathrm{OKC}$ is thought to take a different growing mechanism and biologic behavior from the common odonotogenic cyst, such as dentigerous cyst and radicular cyst (1). Todd et al. reported that the recurrence rate of $\mathrm{OOC}$ was $2.2 \%$ as compared with recurrence rate of at least $42.6 \%$ for OKC (5). Therefore, compared with OKC, OOC showed other biological behaviors $(5,6,8)$. Moreover, hitstopathologically, OOC is very similar to $\operatorname{EDC}(7,10)$. A several studies have reported the immunohistochemical analyze in OKC and $\operatorname{OOC}(3,5,7,8,9)$, however, the conclusive results have not yet been reported. For that reason, this study focused on identifying differences among OKC, OOC and EDC using immunohistochemical techniques.

$\mathrm{Ki}-67$ is a nuclear antigen expressed during all phases of

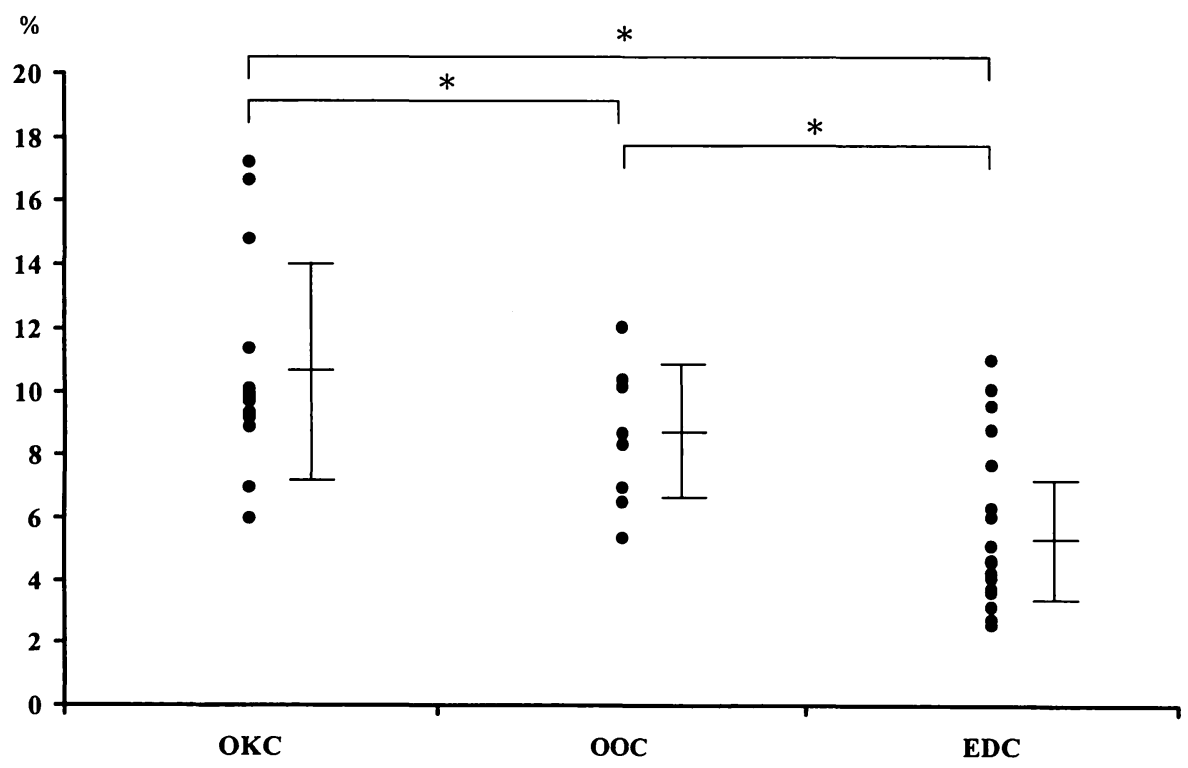

Fig. 4. Distribution of the Ki-67 labeling index. OKC: $10.7 \pm 3.3 \%$ (mean \pm SD) $n=14$. OOC: $8.6 \pm 2.1 \%$ $\mathrm{n}=9$. EDC: $5.7 \pm 2.6 \%=18$. Statistical difference. $* P<0.05$ 
Table 3. Immunohistochemical staining patterns of the lining epithelium among the three cysts

\begin{tabular}{|c|c|c|c|c|c|c|c|c|c|c|}
\hline Epithelial layers & $\mathrm{Ki}-67$ & CK7 & CK10 & CK13 & CK17 & CK18 & CK19 & CK20 & bcl-2 & Bax \\
\hline \multicolumn{11}{|l|}{$\mathrm{OKC}$} \\
\hline Parakeratinized cells & - & - & $*+$ & ++ & ++ & - & + & - & - & + \\
\hline Upper suprabasal cells & - & - & - & ++ & ++ & - & + & - & - & + \\
\hline Suprabasal cells & ++ & - & - & - & ++ & - & - & - & - & + \\
\hline Basal cells & + & - & - & - & ++ & - & - & - & ++ & ++ \\
\hline \multicolumn{11}{|l|}{ OOC } \\
\hline Surface keratinized cells & - & - & ++ & $*++$ & $*+$ & - & - & - & - & - \\
\hline Granular cells & - & - & ++ & $*++$ & - & - & - & - & - & + \\
\hline Spinous cells & + & - & $*++$ & - & - & - & - & - & - & + \\
\hline Basal cells & + & - & - & - & - & - & - & - & - & + \\
\hline \multicolumn{11}{|l|}{$\mathrm{EDC}$} \\
\hline Surface keratinized cells & - & - & ++ & $*++$ & $*+$ & - & - & - & - & - \\
\hline Granular cells & - & - & ++ & - & - & - & - & - & - & + \\
\hline Spinous cells & - & - & ++ & - & - & - & - & - & - & + \\
\hline Basal cells & + & - & - & - & - & - & - & - & - & + \\
\hline
\end{tabular}

- negative staining; + slightly to moderately positive staining; ++ strongly or intensely positive staining; $*$ focal reaction

the cell cycle $\left(G_{1}, S, G_{2}, M\right)$ except for the resting phase $\left(\mathrm{G}_{0}\right)$, and the expression is maximal in the $S$ phase, rapidly decreasing from $\mathrm{M}$ phase (14-16). Therefore, Ki-67 is applicable for determining of cell's proliferation. The growth of tumorous lesions depends on the cellular proliferative activity. Many studies comparing with malignant, benign and normal tissue using $\mathrm{Ki}-67$ have been reported that $\mathrm{Ki}$ 67 labeling index corresponds with the degree of malignancy (17-19). In oral lesions, ameloblastoma, which is the most common benign odontogenic tumor, was from 4.3 to $6.8 \%$ of Ki-67 labeling index (20-21). On the other hand, Kimi et al. reported $\mathrm{Ki}-67$ labeling index in $\mathrm{OKC}$ was $11.2 \%$ and $\mathrm{OOC}$ was $7.8 \%$ (3). The present data of OKC and OOC are similar to Kimi's results. Moreover, Takahashi et al. used proliferating cell nuclear antigen, reported that $\mathrm{OKC}$ had statistically higher cellular activity than that of ameloblastoma, which suggested that odontogenic keratocyst was regarded as benign odontogenic tumours (22). The present study revealed that the Ki-67 labeling index of OKC showed the highest cell proliferation and also suggested that OKC was characterized as a benign tumor like lesions. There were a statistically significant among OKC, OOC and EDC $(p<0.05)$. And the localization of Ki67-positive nuclei was different among $\mathrm{OKC}$, OOC and
EDC. Since, these findings might be due to the various degrees of maturation and the cell proliferative activity in epithelium, OOC was an intermediate character between $\mathrm{OKC}$ and EDC.

Keratin is a major cytoskeletal protein in almost epithelial cells, and at least, 20 different subtypes of cytokeratins have been identified in human tissue (11). According to the molecular weight, acidic and basic forms based on isoelectric point, the CKs are divided into two groups, type I (CK9 20, pKi: 4 6, molecular weight: 40 64kD) and type II (CK1 8, pKi: 7 8, molecular weight: 52.5 68kD) $(11,23)$. The CKs composition may reflect the stage of development of epithelial cells, as well as different tissue's epithelia (24). Therefore, the $\mathrm{CK}$ are useful for distinction among OKC, OOC and EDC.

CK10 is specific on cornified surfaces like skin (25). One of the major finding in this study was the absence of CK10 in most of OKCs (except for some cases of forcal reaction in the parakeratinized layer), contrastively, CK10 was presence in upper spinous cells of OOC and EDC. It was possible parakeratinization or orthokeratinization was programmed in the basal cells.

Concerning CK13 staining, similar pattern was observed in OKC and OOC, although the other CK subtypes showed 
similar finding between OOC and EDC. This result suggests that the quality of orthokeratinization would be a little different between OOC and EDC.

CK17 showed a great difference of expression from other CKs. The expression of CK17 in OKC was widely and strongly positive in all epithelia, but in OOC and EDC was weakly and locally positive in keratinized cells. Generally, CK17 is different from other CKs, in that its expression is not linked with the well-defined program of terminal differentiation $(11,22)$, but appears overgrowth cases (11). In addition, CK 17 expression is more widespread in undifferentiated squamous cell carcinoma than in well or moderately differentiated squamous cell carcinoma (23). In this series, most OKCs showed a strong and uniform staining intensity in all levels of the epithelium including the parakeratinized layer. This indicated that $\mathrm{OKC}$ was more aggressive than OOC and EDC, and therefore CK17 might be a useful marker to distinguish OKC from other two types of cysts. Since CK17 was also known to be expressed in the 'humidity' stratified epithelia (23), the wet cystic environment might influence the expression of CK17 on the surface keratinized cells of OOC and EDC.

CK19 is thought to be an odontogenic epithelium marker as it is used frequently in tumors of odonotogenic origin, such as ameloblastoma, odontogenic myxoma and clear cell odontogenic carcinoma $(23,26)$. In this study, OKC showed an intense expression of CK19 in the parakeratinized cells and upper suprabasal cells of the epithelial lining, but CK19 did not found in OOC and EDC. Although, OKC arises from cell rests of the dental lamina (1), the OOC might take its origins from other cell rests such as gingival cells and mucosal cells.

CK7, CK18 and CK20 are expressed in the simple epithelia, including many ductal and glandular epithelia (23). The present results of three cysts were negative for CK7, CK18 and CK20. This results suggested that these epithelial cyst linings were neither simple nor neoplastic, but comparatively differentiated stratified squamous epithelia.

The bcl-2 proto-oncogene is a member of a gene family in the suppressors of the programmed cell death $(17,27$ 29). Recent studies have suggested that there is a close relationship between bcl-2 protein expression and cell population which are long lived, and/or with high proliferation ability $(3,29)$. Immunoreactivity for bcl-2 protein has been detected in the enamel organs and the dental lamina of tooth germs as well as in most neoplastic cells of ameloblastoma $(3,30)$. OKC showed more aggressive clinical behavior, higher recurrence rate, and a higher proliferative activity than those of OOC and EDC. In this study, bcl-2 was positive staining in the basal cells of OKC, but negative reaction for any cells of the OOC and EDC. These results reflected the different clinical feature of $\mathrm{OKC}$, OOC and EDC.

Bax is one of the members of the bcl-2 family $(27,31)$. Overexpression of Bax homodimers increases the susceptibility of the cells to apoptosis $(26,31)$. Since the present results indicate that $\mathrm{Bax}$ was expressed in most cases of OKC, OOC and EDC, Bax might contribute of keratinization.

In conclusion, the present study suggests that there are immunohistochemical differences among $\mathrm{OKC}, \mathrm{OOC}$ and EDC. Immunohistochemical results showed that OKC had high cellular proliferation and was relatively low differentiation as compare with OOC and EDC. In addition, there was participation of apoptosis suppressor in OKC. The cellular activity of OOC was intermediate position $\mathrm{OKC}$ and EDC. Add to this, OOC and EDC showed similar reactivity against $\mathrm{CKs}$ and bcl-2. Therefore, it was possible to consider OOC as a distinct entity from OKC. EDC had the lowest cellular activity in the three cysts and it was comparatively maturative lesion.

\section{Acknowledgments}

The author is grateful to Professor H. Yamamoto (Department of Pathology, Nihon University School of Dentistry at Matsudo) for his direction and helpful advice, and appreciates Professor Y. Akimoto, Y. Kozawa and Y. Ogata (Departments of Oral Surgery, Anatomy and Periodontology, Nihon University of Dentistry at Matsudo) for reviewing the manuscript. And author also would like to thank Professor Y. Yamaguchi (Department of Clinical Pathology, Kashiwa Hospital, Jikei University) and acknowledge our colleagues belong to Department of Pathology for their excellent supports.

\section{References}

1. Brad WN, Douglas DD, Carl MA, Jerry EB: Developmental Defects of the Oral and Maxillofacial Region and Odontogenic Cysts and Tumors. In: Brad WN, Douglas DD, Carl MA, 
Jerry EB. Oral and Maxillofacial Pathology. Second edition. W. B. Saunders Co, Philadelphia, 2002, pp 31-32 and 594598.

2. Takagi M: Atlas of Oral Pathology: 1998, Bunkoudou, Tokyo, Japan (in Japanese).

3. Kimi K, Kumamoto H, Ooya K, Motegi K: Analysis of Apoptosis-related Factors and Apoptotic Cells in Lining Epithelium of Odontogenic Keratocysts. Oral Med Pathol, 5: 35-40, 2000.

4. Regezi JA: Odontogenic Cysts, Odontogenic Tumors, Fibroosseous, and Giant Cell Lesions of the Jaws. Mod Pathol, 15: 331-341, 2002.

5. Crowley TE, Kaugars GE, Gunsolley JC: Odontogenic Keratocysts: A Clinical and Histologic Comparison of the Parakeratin and Orthokeratin Variants. J Oral Maxillofac Surg, 50: 22-26, 1992.

6. Wright JM: The Odontogenic Keratocyst: Orthokeratinized Variant. Oral Surg Oral Med Oral Pathol, 51: 609-618, 1981.

7. Vuhahula E, Nikai H, Ijuhin N, Ogawa I, Takata T, Koseki T: Jaw Cysts with Orthokeratinization: Analysis of 12 Cases. J Oral Pathol Med, 22: 35-40, 1993.

8. Li TJ, Kitano M, Chen XM, Itoh T, Kawashima K, Sugihara $\mathrm{K}$ : Orthokeratinized Odontogenic Cyst: A Clinicopathological and Immunocytochemical Study of 15 Cases. Histopathology, 32: 242-251, 1998.

9. Silva MJ, de Sousa SO, Correa L, Carvalhosa AA, De Araujo VC: Immunohistochemical Study of the Orthokeratinized Odontogenic Cyst: A Comparison with the Odontogenic Keratocyst. Oral Surg Oral Med Oral Pathol Oral Radiol Endod, 94: 732-737, 2002.

10. Yago K, Tanaka, Y, Ousaka, F, Uetake A, Okada Y, Asanami S: A Clinical and Histopathological Study of Cysts with Keratinized Epithelium in the Jaws. Jpn J Oral Surg, 40: 841851, 1994 (in Japanese).

11. Tamaki K: Comprehensive Handbook of Clinical Dermatology vol. 7, 2002, Nakayamasyoten, Tokyo, Japan (in Japanese).

12. Kerr JF: Shrinkage Necrosis: A Distinct Mode of Cellular Death. J Pathol, 105: 13-20, 1971.

13. Krajewska M, Fenoglio-Preiser CM, Krajewski S, Song K, Macdonald JS, Stemmerman G, Reed JC: Immunohistochemical Analysis of Bcl-2 Family Proteins in Adenocarcinomas of the Stomach. Am J Pathol, 149: 14491457, 1996.

14. Zachariades N, Papanicolaou S, Triantafyllou D: Odontogenic Keratocysts: Review of the Literature and Report of Sixteen Cases. J Oral Maxillofac Surg, 43: 177-182, 1985.

15.Shear M: The Aggressive Nature of the Odontogenic Keratocyst: Is it a Benign Cystic Neoplasm? Part 3. Immunocytochemistry of Cytokeratin and Other Epithelial Cell Markers. Oral Oncol, 38: 407-415, 2002.

16. Brown DC, Gatter KC: Monoclonal Antibody Ki-67: Its Use in Histopathology. Histopathology, 17: 493-503, 1990.

17. Amatya VJ, Takeshima Y, Sugiyama K, Kurisu K, Nishisaka T, Fukuhara T, Inai K: Immunohistochemical Study of Ki-67
(MIB-1), p53 protein, p21WAF1, and p27KIP1 Expression in Benign, Atypical, and Anaplastic Meningiomas, Hum Pathol, 32: 970-975, 2001.

18. Mirtti T, Kallajoki M, Aaltonen M, Alanen K: Cyclin A and Ki-67 with DNA Content in Benign and Malignant Prostatic Epithelial Lesions, Anal Quant Cytol Histol, 23: 229-237, 2001.

19. Hirabayashi S: Immunohistochemical Detection of DNA Topoisomerase Type II alpha and Ki-67 in Adenoid Cystic Carcinoma and Pleomorphic Adenoma of the Salivary Gland, J Oral Pathol Med, 28: 131-136, 1999.

20. Sandra F, Mitsuyasu T, Nakamura N, Shiratsuchi Y, Ohishi M: Immunohistochemical Evaluation of PCNA and Ki-67 in Ameloblastoma. Oral Oncol, 37: 193-198, 2001.

21. Rosenstein T, Pogrel MA, Smith RA, Regezi JA: Cystic Ameloblastoma-Behavior and Treatment of 21 Cases, J Oral Maxillofac Surg, 59: 1311-1318, 2001.

22. Takahashi H, Fujita S, Yamabe S, Moriishi T, Okabe H, Tajima Y, Mizuno A: Comparison of Proliferating Cell Nuclear Antigen Expression in Odontogenic Keratocyst and Ameloblastoma: An Immunohistochemical Study. Anal Cell Pathol, 16: 185-192, 1998.

23. Chu PG, Weiss LM: Keratin Expression in Human Tissues and Neoplasms. Histopathology, 40: 403-439, 2002.

24. Bloor BK, Seddon SV, Morgan PR: Gene Expression of Differentiation-specific Keratins (K4, K13, K1 and K10) in Oral Non-dysplastic Keratoses and Lichen Planus. J Oral Pathol Med, 29: 376-384, 2000.

25. August M, Faquin WC, Troulis M, Kaban LB: Differentiation of Odontogenic Keratocysts from Nonkeratinizing Cysts by Use of Fine-Needle Aspiration Biopsy and Cytokeratin-10 Staining. J Oral Maxillofac Surg, 58: 935-941, 2000.

26. Kumamoto H, Yoshida M, Ooya K: Immunohistochemical Detection of Amelogenin and Cytokeratin 19 in Epithelial Odontogenic Tumors. Oral Dis, 7: 171-176, 2001.

27. Sellheyer K, Krahl D, Ratech H: Distribution of Bcl-2 and Bax in Embryonic and Fetal Human Skin: Antiapoptotic and Proapoptotic Proteins are Differentially Expressed in Developing Skin. Am J Dermatopathol, 23: 1-7, 2001.

28. Lu QL, Abel P, Foster CS, Lalani EN: Bcl-2: Role in Epithelial Differentiation and Oncogenesis. Hum Pathol, 27: 102-110, 1996.

29. Sandra F, Nakamura N, Mitsuyasu T, Shiratsuchi Y, Ohishi M: Two Relatively Distinct Patterns of Ameloblastoma: An Anti-apoptotic Proliferating Site in the Outer Layer (Periphery) and a Pro-apoptotic Differentiating Site in the Inner Layer (Centre). Histopathology, 39: 93-98, 2001.

30. Mitsuyasu T, Harada H, Higuchi Y, Kimura K, Nakamura N, Katsuki T: Immunohistochemical Demonstration of Bcl-2 Protein in Ameloblastoma. J Oral Pathol Med. 26: 345-348, 1997.

31. Arasaki H, Kuyama K: An Immunohistochemical Study of Expression of p53 and Apoptosis-associated Markers and Detection of Apoptosis in Oral Mucosal Diseases. Nihon Univ. J. Oral. Sci, 26: 127-138, 1999 (in Japanese). 